Discussion Paper No. 10-062

Regulation of Pharmaceutical Prices:

Evidence from a

Reference Price Reform in Denmark

Ulrich Kaiser, Susan J. Mendez, and Thomas Rønde

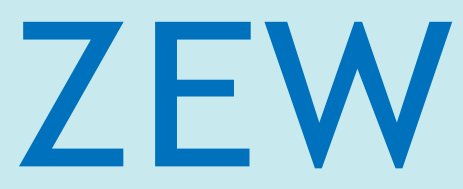

Zentrum für Europäische Wirtschaftsforschung $\mathrm{GmbH}$

Centre for European

Economic Research 
Discussion Paper No. 10-062

\section{Regulation of Pharmaceutical Prices:}

Evidence from a

Reference Price Reform in Denmark

Ulrich Kaiser, Susan J. Mendez, and Thomas Rønde

Download this ZEW Discussion Paper from our ftp server:

ftp://ftp.zew.de/pub/zew-docs/dp/dp10062.pdf

Die Discussion Papers dienen einer möglichst schnellen Verbreitung von neueren Forschungsarbeiten des ZEW. Die Beiträge liegen in alleiniger Verantwortung der Autoren und stellen nicht notwendigerweise die Meinung des ZEW dar.

Discussion Papers are intended to make results of ZEW research promptly available to other economists in order to encourage discussion and suggestions for revisions. The authors are solely responsible for the contents which do not necessarily represent the opinion of the ZEW. 


\section{Executive summary}

This paper studies the effects of a reference price reform in Denmark on price and demand for statins, products that reduce the blood cholesterol levels. Too high cholesterol levels may cause cardiovascular diseases. Reference pricing is a cost containment tool that is applied to reduce health expenditures in 19 European countries as well as Australia, British Columbia and New Zealand.

Our paper is the first to combine price data and demand data to study reform effects. We produce estimates for changes in total government (health care) expenditures, patient expenditures, patient welfare and producer revenues.

A main finding is that government and patients did indeed benefit in terms of price declines and declining total expenditures from the reform while producers incurred losses.

There are, however, striking differences between products that were "cheap" before the reform and those that were "expensive" before the change. The benefits to patients and the government were primarily due to the initially expensive products. The reform effects were hence quite asymmetrically distributed across products (and thus patients).

We also show that an empirical analysis of the reform effects that studies price changes only may lead to quite misleading implications for welfare analysis. 


\section{Das Wichtigste in Kürze}

Diese Arbeit analysiert die Auswirkungen einer Reform des Referenzpreissystems in Dänemark auf Preise und Nachfrage von Statinen, Produkte, die den Cholesteringehalt des Blutes reduzieren. Zu hohe Cholesterinwerte können mit dem Herz- Kreislaufsystem hervorrufen. Referenzpreise werden in 19 europäischen Ländern sowie Australien, British Columbia und Neuseeland.

Unsere Arbeit ist die erste, die Preis- und Mengendaten gemeinsam analysiert, um Reformeffekte zu berechnen. Wir ermitteln die Veränderungen in Gesundheitsausgaben, den Patienten-Zuzahlungen, der Patienten-Wohlfahrt und den Erlösen der Hersteller.

Ein Hauptresultat ist, dass das Gesundheitssystem und die Patienten von der Reform profitiert haben in Termini von gesunkenen Preises und Gesamtausgaben. Die Hersteller der Medikamente haben hingegen Verluste erlitten.

Es bestehen allerdings grosse Unterschiede in der Verteilung der Veränderungen. Produkte, die vor der Reform relativ billig waren, haben ihre Preise wesentlich weniger gesenkt (bzw. sogar erhöht) als solche, die vor der Reform teuer waren. Die Verbesserung der Situation von Patienten und dem Gesundheitssystem ist vor allem den Produkten zu verdanken, die vor der Reform relativ teuer waren. Die Reformeffekte sind also sehr asymmetrisch verteilt über die Produkte (und daher auch über die Patienten)

Wir zeigen ebenso, dass eine Analyse von Reformeffekten, die alleine auf Preisen beruht, zu recht irreführenden Wohlfahrtsimplikationen mündet. 


\title{
Regulation of pharmaceutical prices: evidence from a reference price reform in Denmark
}

This version: August 20, 2010

\author{
Ulrich Kaiser*, Susan J. Mendez**, \\ and THOMAs RøNDE ${ }^{\|}$
}

\begin{abstract}
On April 1, 2005, Denmark changed the way references prices, a main determinant of reimbursements for pharmaceutical purchases, are calculated. The previous reference prices, which were based on average EU prices, were substituted to minimum domestic prices. Novel to the literature, we estimate the joint effects of this reform on prices and quantities. Prices decreased more than 26 percent due to the reform, which reduced patient and government expenditures by 3.0 percent and 5.6 percent, respectively, and producer revenues by 5.0 percent. The prices of expensive products decreased more than their cheaper counterparts, resulting in large differences in patient benefits from the reform.
\end{abstract}

JEL-classification: I18, C23

Keywords: pharmaceutical markets, regulation, co-payments, reference pricing, asymmetric welfare efffects

\footnotetext{
"We thank Friedrich Breyer, Werner Güth, Felix Höffler, Margaret Andrew Toole and Hannes Ullrich for helpful comments. We also benefited from comments received at the 10th Symposium of the German Economic Association of Business Administration in Vallendar, the 39th Economic Seminar Ottobeuren as well as seminar presentations in Konstanz and Zurich. The paper also gained greatly from extensive discussions with Margaret Kyle and Saul Lach. We are very much indebted to Jørgen Clausen of the Danish Association of the Pharmaceutical Industry (Lægemiddel Industri Foreningen, LIF) for data provision and data advice. Excellent medical advice was provided to us by the MDs Marit Otto, Roland Knudsen and in particular Johannes Schmid. Financial support from the Economic Policy Research Network is gratefully acknowledged.

*University of Zurich, Institute for Strategy and Business Economics, Plattenstr. 14, 8032 Zurich, Switzerland, ulrich.kaiser@isu.uzh.ch; Centre for Economic and Business Research at Copenhagen Business School; Centre for European Economic Research, Mannheim; Centre for Industrial Economics at the University of Copenhagen and Institute for the Study of Labor, Bonn.

${ }^{* *}$ University of Zurich, Institute for Strategy and Business Economics, Plattenstr. 14, 8032 Zurich, Switzerland, susan.mendez@isu.uzh.ch;

${ }^{\|}$Copenhagen Business School, Department of Innovation and Organizational Economics, Kilevej 14A, 2000 Frederiksberg, Denmark, thr.ino@cbs.dk; Centre for Economic and Business Research at Copenhagen Business School; Centre for European Economic Research, Mannheim; Centre for Industrial Economics at the University of Copenhagen and Centre for Economic Policy Research, London.
} 


\section{Introduction}

Given steady growth in life expectancy, aging populations in many countries, and the expected launch of new and ever more expensive medical treatments, expenditures for pharmaceutical products are expected to increase substantially in the years to come. This has led (and continues to lead) governments around the world to regulate the market for pharmaceuticals using cost containment tools such as price caps, price agreements with producers, generic substitution schemes, prescription behavior monitoring and reference prices.

Denmark, which maintains a universal coverage health care system, introduced reference pricing in 1993 whereby a patient is reimbursed a fraction of the retail price when buying a prescription drug. Prior to April 1, 2005, the reference price was calculated as the minimum of either the list price a product's own substitution group or the respective European average price. In general, for products where the Danish prices were below the European average price, patients had little incentive to buy the cheapest product because the public health insurance paid the major part of the price difference between the cheapest product and the desired substitute. To increase the price sensitivity of patients and to sharpen competition, reference prices were changed to be the minimum Danish price among products in the same substitution group on April 1, 2005. ${ }^{1}$ This paper investigates the effects of this reference price reform.

The use of reference pricing as an indirect tool for controlling prices was first introduced in Germany in 1989, and it has been adopted by many European countries since then. In a recent survey, Puig-Junoy (2010) reports that 19 out of 26 European countries use reference pricing. Outside Europe, reference pricing is applied in Australia, New Zealand and in the Canadian province of British Columbia (Heuer et al., 2007). Economic evidence of the effects of reference pricing is somewhat scarce, but the literature has generally shown that the introduction of reference pricing reduces prices (Brekke et al., 2009a, 2009b; Kanavos et al., 2008; Pavcnik, 2002). ${ }^{2}$ However, the insights that these studies provide is limited by the fact that they either only look at price effects (Brekke et al. 2009a; Kanavos et al., 2008; Pavcnik, 2002) or the quantity effects of reference pricing (Kanavos et al., 2008; Puig-Junoy, 2007). ${ }^{3}$

From these studies, it is not possible to draw conclusions regarding the effects of reference pricing based on the surplus of the parties involved because this requires a

\footnotetext{
${ }^{1}$ In Denmark, a substitution group is defined by the Danish Medicine Agency (DKMA) as products based on the same molecule of the same strength with the same administration form and a similar package size.

${ }^{2}$ Puig-Junoy (2010) performs an extensive literature search and find only seven empirical studies on reference pricing, of which only three use econometric techniques.

${ }^{3}$ Brekke et al. (2009b) regress the average prices, market shares and average molecule prices on the number of products subject to reference pricing.
} 
joint analysis of price and quantity effects. In this paper, we take a step forward by estimating a demand model that allows us to measure the effect of the Danish reference price reform on patients, producers, and public health insurance. Moreover, as this is the first paper to estimate product-specific rather than average reform effects, we are able to study asymmetric reactions to the reform between high-priced and low-priced products.

We confine our analysis to statins, which are lipid modifying agents (LMAs) that are used to treat high levels of cholesterol. The best known statins sell under the names "Lipitor" and "Zocor." Statins grew massively in popularity in Denmark after a large-scale medical trial in Scandinavia in the 1990s showed that treatment with simvastatin, the most popular statin, decreases mortality and morbidity of patients with cardiovascular diseases (Scandinavian Simvastatin Survival Study Group, 1994). Statins are widely prescribed drugs today and have experienced rapidly increasing demand in the past years all over the world. They currently constitute the best-selling drugs in terms of sales both in Denmark and worldwide.

Our empirical strategy is to first estimate the product-specific effect of the reform on prices of a so-called "Defined Daily Dose" using the Pooled Mean Group Estimator suggested by Pesaran and Smith (1995). ${ }^{4}$ Second, we estimate a structural model for the demand for statins using a nested logit model of product differentiation (Anderson et al. 1992; Berry 1994), a standard discrete choice model with random consumer utility. Third, we map the estimated price effects of the reform to our demand system estimates to find the demand changes that the health care reform induced. Finally, we calculate the total changes in patient co-payments, patient surplus, government expenditures and producer revenues. We hence predict the changes the reform would have had had it been implemented in the base period already. The counter-factual question we ask is "what would the market have looked like had the reform been implemented under the conditions of the base period?" By constructing a counterfactual base period market from our estimated price changes, we effectively "filter out" any changes in the market that was not induced by the reform.

We should note that our study is confined to the effects of the reform on those products that were on the market both before and after the reform; i.e., we are concerned with the so-called "treatment effect on the treated" as it is referred to in the program evaluation literature. Thus, similar to existing related studies, we are unable to draw any inference about products that entered or left the market after the reform was implemented.

\footnotetext{
${ }^{4}$ A "Defined Daily Dosage" (DDD) is a unit of measure of drug consumption issued by the World Health
} Organization that is used to standardize the comparative usage of drugs. A DDD is assumed to be the average dose per day for a drug when used for its main indication in adults. 
Our results support previous studies by finding a substantial decrease in prices after the reform. List prices decreased by 26.6 percent on average, and reference prices decreased 31.8 percent on average. The average decrease in co-payments is estimated at 7.5 percent. These price changes are associated with an increase in total demand by 1.9 percent per 14 days, which is the periodicity of our data. Total producer revenues decreased by 5 percent, total government expenditures decreased by 5.6 percent, and total patient expenditures decreased by 3 percent. Finally, patient surplus increased by 8.2 percent.

Our estimates for the full reform effect take into account the fact that changes in demand patterns differ substantially from the findings we obtain when we assume that demand stays constant. Indeed, if patients had not reacted to the price changes the reform brought about by changing their consumption behavior, their total expenditures would have increased by as much as 10.2 percent. Similarly, government expenditures and producer revenues would have increased by 14.9 percent and 13.7 percent, respectively. This illustrates the importance of considering both price and quantity effects when evaluating the effects of the regulatory reform in health care.

The price effects of a reform are large but also quite asymmetrically distributed across products, which is an aspect that our fully flexible price estimation method is able to capture. The list prices of the initially cheap products in a substitution group decreased by 5.8 percent, and they decreased by as much as 44.4 percent for the initially expensive products. This asymmetry in the effects between initially high-priced and initially low-priced products implies that patients who purchased cheap products before the reform were actually made worse off, while patients who initially bought the initially more expensive products were made substantially better off. Furthermore, we also find that list prices and reference prices decreased substantially more for products belonging to the expensive substitution groups than for products belonging to the cheap substitution groups. Our results show that the Danish reference price reform led to significant total gains for patients and public health insurance but that they are, however, asymmetrically distributed.

The question remains as to what extent these results can be generalized to other countries. While the national rules and regulations concerning, e.g., generic substitution and mark-ups by pharmacies undoubtedly are important for the size of the gains that reference pricing can bring about, we believe that the Danish experience contains some general insights regarding how a reference price should be chosen. In particular, we argue that defining the lowest price in the substitution group as the reference price has a number of attractive properties that stimulate competition and bring down the prices of off-patent drugs. First, because patients pay the full price difference out-of- 
pocket when buying a product that is not the cheapest one, they are as price sensitive as they would be without reimbursement from the health insurance. A price elastic demand, in turn, results in tougher competition and lower prices. Second, using the European average price, or any other external benchmark, as the reference price makes demand more price elastic above the reference price than below it. This introduces a tendency for prices to cluster at the reference price (Danzon and Liu, 1998). For such a system to work well, it requires that policy makers are able to perform the difficult task of setting reference prices close to the competitive level; this is a problem that they do not face when the reference price is defined as the lowest price in the substitution group. In this sense, the Danish reference price reform shows that the best institution at setting competitive prices is the market. ${ }^{5}$

This paper is organized as follows. Section 2 reviews the existing related literature, and Section 3 provides an overview of the market for pharmaceutical products and introduces the Danish institutional setting. Section 4 describes the data. Section 5 provides some theoretical considerations and Section 6 describes the reform effects on prices. Section 7 describes the empirical strategy. Section 8 presents our estimation results and discusses some policy implications. Section 9 provides a robustness check and Section 10 concludes.

\section{$2 \quad$ Existing studies}

This section discusses the studies mentioned in the Introduction in more detail and briefly reviews other papers relevant to our analysis. As the first paper that investigated the implementation of reference pricing, Pavcnik (2002) finds price reductions of 10 to 26 percent following the introduction of reference pricing in Germany in 1989. In their cross-country analysis, Kanavos et al. (2008) study the effects of reference pricing on the number of competing producers, the originator price, the generic price, the lowest price of generic products, and total sales volumes. They find that reference pricing encourages generic entry and reduces the prices of generic products. The average price reduction of the generic products is between 2 and 3 percent, but the price of the cheapest product is reduced by as much as 47 percent. Puig-Junoy (2007) analyzes the effects of a series of reference price reforms on the demand for statins, which is

\footnotetext{
${ }^{5} \mathrm{~A}$ number of solutions to the problem of setting references prices have been implemented in different countries; see ÖBIG (2008). In Germany, reference prices are set by the Association of Sickness Funds (BKK) using a hedonic price estimation procedure that is subject to the restriction that the reference price must be within the 33rd percentile of the price distribution. The Netherlands, which defines substitution groups based on therapeutic effects, defined the 1990 median price of a daily dose in the substitution group as the reference price. These 1990indexed reference prices were kept until 1999. In Portugal, the reference price is defined as the price of the most expensive generic product in the substitution group.
} 
also the product considered in this paper, in Spain and its province Andalusia. He regresses total demand for statins on a set of dummy variables for the adoption of reforms by the respective regions. His analysis lacks counterfactual price data, and it is thus implicitly assumed that the coefficients on the time dummy variables are solely driven by the reform. In contrast, our demand estimates relate to the period before the reform only so that we remove any other events that may have occurred after the reform was implemented.

Related to our paper, albeit less directly, there is a series of papers that study the effects of a switch from price cap regulation to reference pricing in Norway. These papers confirm the efficiency of reference pricing in bringing the prices of pharmaceutical products down and show how the Norwegian reform resulted in a substantial decrease in prices (Brekke et al., 2009a, 2009b) as well as in a reduction in producer market power (Dalen et al., 2006). Finally, there are a number of papers that study the effects of reference pricing in game-theory frameworks. A variety of issues have been analyzed, such as the effects of different choices of reference prices on equilibrium price levels (Mestre-Ferrándiz, 2003; Merino-Castelló, 2003), the choice between generic and therapeutic substitution groups (Brekke et al., 2007), and so-called "ratchet effects" resulting from reference pricing (Miraldo, 2009).

\section{The Danish market for pharmaceutical products}

\subsection{General settings}

As in other European countries, the market for pharmaceutical products in Denmark is regulated. Denmark follows European regulations regarding product authorization. Product pricing, reimbursement rules and the regulation of pharmacies are national matters. The number of pharmacies, their location and total gross profit is determined by the Danish Ministry of Health and Prevention. Prices for prescription-only products are identical nationwide. However, pharmacies may compete on over-the-counter products, which may also be sold by non-pharmacies.

The pricing of pharmaceutical products in Denmark is free in the sense that producers are not tied to any regulation regarding price-setting. However, they are required to notify their pharmacy purchase price to the Danish Medicines Agency (DKMA) every 14 days.

In Denmark, every resident is entitled to free and equal access to tax-supported health care services regardless of her employment status or health status. In the provision of pharmaceutical products, the government reimburses expenditures for prescription drugs based on the respective reference price. 
Even though the popularity of additional private insurance has increased lately, it was not very common during the period we study. In 2000, over 70 percent of the population was covered only by the statutory health insurance. The dominant player in private insurance, which practically held a monopoly, is "Sygeforsikringen Danmark." Its most popular insurance plan pays 50 percent of the patient's co-payments and covers 80 percent of all subscribers to Sygeforsikringen Danmark. We do not have information on private insurance membership, which means that we cannot address possible selection problems arising from additional private coverage. We speculate that the problem of the possible existence of private insurance is not an important one because the fraction of private insurance subscribers is small and because it is not clear if more healthy individuals subscribe to private insurance (i.e., in order to hedge against future illness and because they have no difficulties being admitted) or if less healthy individuals subscribe (i.e., to reduce their patient co-payments).

\subsection{Pharmacies and physician incentives}

It is important to note that neither pharmacies nor physicians have any incentives to sell patients a particular product. First, advertising prescription drugs to patients is prohibited in Denmark. Second, detailing of established drugs such as statins is regulated and does not appear to play an important role. We lack concise information about detailing, but based on conversations with many health professionals, we believe that detailing rarely occurs, and when it does occur, it is related to drugs that are new to the Danish market. Third, pharmacy profits from selling prescription drugs are set by the government and are independent of the prices at which the drugs are being sold.

\subsection{List prices and co-payments}

Our data set contains fortnightly prices and sales of statins for the period between September 15, 2003, and October 9, 2006. Our price data, including reference prices, can be downloaded from www.medicinpriser.dk.

Patient co-payments for statins are defined as $p^{c}=p^{l}-\left(0.8 p^{r}\right)$, where $p^{c}$ denotes the patient co-payment, $p^{l}$ is the list price, and $p^{r}$ denotes the price of the reference product. The minimum co-payment for each patient is 20 percent of the list price (when list prices and reference prices coincide). The reimbursement rate actually depends on a patient's total expenses for pharmaceutical products. However, according to our medical advisors, patients who receive statin treatment easily exceed the expenditures threshold needed to obtain a reimbursement rate of 80 percent, even if they always buy the cheapest statin. In addition, many patients treated with statins need 
to take other products for cardiovascular diseases like blood thinners or beta blockers, thus increasing their expenditures further. The co-payment fraction is unaffected by the health care reform.

\subsection{The April 2005 reference price reform}

The reform that this paper investigates involves the change in the way reference prices, $p^{r}$, are calculated. Before April 1, 2005, reference prices were based on average prices among the EU-15 members, excluding Greece, Luxembourg, Spain, and Portugal. The reference price for a given product was the minimum EU-15 average price among the products belonging to the same substitution group, $p^{E U} .{ }^{6}$ However, if a product's list price, $p^{l}$ was below $p^{E U}$, the reference price was equal to the list price. ${ }^{7}$ Since April 2005 , the reference price for a product is the minimum domestic price among the products belonging to the same substitution group, $p_{\text {min }}^{l}$, and is updated fortnightly as the new prices are announced. More formally, reference prices before the reform, $p_{\text {before }}^{r}$, and references prices after the reform, $p_{\text {after }}^{r}$, are defined as follows:

$$
\begin{aligned}
p_{\text {before }}^{r} & =\left\{\begin{array}{cc}
p^{E U} & \text { if } p^{l} \geq p^{E U} \\
p^{l} & \text { otherwise }
\end{array}\right. \\
p_{\text {after }}^{r} & =p_{\text {min }}^{l},
\end{aligned}
$$

To favor generic substitution, the so-called "G Scheme" was introduced in 2001. This scheme states that pharmacists are obligated to dispense the cheapest product within a group of substitutes unless the prescription explicitly requires no substitution, which is the case for just 5 percent of all prescriptions, or the patient explicitly requests another product. If the patient prefers a more expensive product, she must pay the difference out of her own pocket. Table 1 provides an example. Suppose a patient can choose among three products A, B and C. Before the reform, the patient obtains the maximal reimbursement rate when buying products $\mathrm{A}$ and $\mathrm{B}$. After the reform, the reference price is equal to the price of the cheapest product in Denmark $\left(p_{\text {After }}^{r}=100\right.$ DKK), and the patient only obtains the maximal reimbursement rate when buying product $\mathrm{A}$.

\footnotetext{
${ }^{6}$ If a European average price did not exist for a product, the reference price was set to be equal to the list price of the cheapest domestic product. For parallel imports, the reference price was defined as the reference price of the directly traded product.

${ }^{7}$ According to a report by the Danish Ministry of Health from 2004, 74 percent of the packages sold on the Danish market were cheaper than the corresponding European package.
} 
Table 1: Example of the calculation of co-payments

\begin{tabular}{ccccccc}
\hline \hline Product & $p^{l}$ & $p^{E U}$ & $p_{\text {before }}^{r}$ & $p_{\text {after }}^{r}$ & $p_{\text {before }}^{c}$ & $p_{\text {after }}^{c}$ \\
\hline $\mathrm{A}$ & 100 & 150 & 100 & 100 & 20 & 20 \\
$\mathrm{~B}$ & 150 & 150 & 150 & 100 & 30 & 70 \\
$\mathrm{C}$ & 200 & 150 & 120 & 100 & 80 & 120 \\
\hline \hline
\end{tabular}

\subsection{Definition of base and treatment periods}

Our empirical analysis is an event study; we investigate changes in pharmaceutical pricing and demand before and after the change in the reimbursement system. There are two relevant dates set by the Danish government. In October 2004, the Danish parliament ratified the new reimbursement law, and on April 1, 2005, the law was implemented.

It is likely that information regarding changes in reimbursement rules had been at the disposal of market participants prior to these two legislatively determined dates. To further investigate this issue, we consulted newspaper and trade press archives by searching for appropriate keywords. It turned out that the Danish Minister of Health announced the assembly of a group of experts with the aim of changing the existing reimbursement system to strengthen competition on September 17, 2003. Moreover, as a member of the working group, the Danish Association of the Pharmaceutical Industry (Lægemiddel Industri Foreningen, LIF) launched the idea of changing the way reference prices are calculated, as was eventually adopted in April 2005.

Between May 2001 and April 2003, LIF maintained an agreement on price ceilings, which was, however, not followed by all LIF members. After the expiration of the agreement, LIF announced a continuation of the price ceiling for another two years. This was a unilateral announcement on the side of LIF rather than an official agreement with the Danish Ministry of Health. As LIF experienced problems enforcing the previous, legally binding agreement, there likely was considerable uncertainty in the market regarding the credibility of the announcement. For this reason, we believe that the announcement by LIF did not influence price-setting in the market in an important way. ${ }^{8}$ Finally, the Danish Ministry of Health and LIF again signed an agreement on a price ceiling in October 2006.

After the price ceiling agreement between LIF and the Danish government expired on June 25, 2003, LIF announced a unilateral extension of the price ceiling for another two years.

\footnotetext{
${ }^{8}$ If the announcement did influence prices, it could either be as a price ceiling that kept prices down or as a coordination device that allowed producers to sustain higher prices. Still, the volatile market structure suggests that price coordination is difficult to sustain (Tirole, 1988).
} 
Notwithstanding, we cannot exclude the possibility that the LIF announcement allowed producers in the market to coordinate higher prices levels (Knittel and Stango, 2003). However, uncertainty regarding the credibility of the LIF announcement, as well as the volatile market structure following the patent expiration at the end of 2002, suggest that price coordination was difficult to sustain. For this reason, we interpret the price development as being the result of the reference price reform, but we are not able to separate the effects of the reform from the possible effects of the LIF announcement.

Insert Table 2 about here.

All five of these events (namely, the expiration of the first LIF pricing agreement, the assembly of the working group, the passing of the reform in parliament, the implementation of the reform and the new LIF pricing agreement) are summarized in Table 2 and shown in Figure 1. This figure plots the number of producers in the market for statins and the median list prices against time. Six different time periods are defined by these events, including the "LIF agreement expiration period," the "adjustment period," the "base period/working group assembly period," the "announcement period," the "implementation period" and the "new LIF agreement period." We discard the two LIF agreement periods as well as the adjustment period after the expiration of the first LIF agreement to avoid including effects other than the actual reform. We define our base period as the period between the working group assembly and the ratification in parliament because it constitutes a period during which there was no information about prospective changes in the reimbursement system and because, presumably for that reason, the number of producers as well as prices remained stable. The "implementation period" constitutes our treatment period. We discard the "announcement period" because it most likely just was a transition period for the producers to prepare for a new competitive setting.

Insert Figure 1 about here.

\section{Data}

\subsection{Definitions}

\section{Product definition}

The aim of any treatment with LMAs is to reduce both the total cholesterol level to below 5 millimol per liter of blood ( $\mathrm{mmol} / \mathrm{l})$ and the level of LDL cholesterol, which is a particularly harmful type of cholesterol, to below $3 \mathrm{mmol} / \mathrm{l}$. A few weeks after a 
LMA treatment has been started, medical practitioners re-evaluate cholesterol levels and may adjust the treatment based on any new information.

Each pharmaceutical product is characterized by its name, package size, administration form, strength, anatomical therapeutic chemical classification code (ATC code) and producer name. A product may, for example, be defined as "Zocor" with 98 tablets à 20 milligram of the active substance simvastatin (ATC C10AA01), produced by Merck Sharp \& Dohme. The ATC-code is a combination of seven letters and numbers that precisely describes a product's active substance.

The products we consider are all pills, coated pills or capsules. The smallest package size is 30 pills, and the largest one is 250 pills. The strength of the products, which is defined as the amount of active substance per pill, also varies considerably, namely, from 5 milligrams to 80 milligrams per pill.

To make comparable the different strengths, package sizes and active ingredients, we converted prices and quantities into DDD. ${ }^{9}$

A total of 95 products existed in the base period, announcement and implementation periods. These constitute the products for which we estimated the reference price reform effects. ${ }^{10}$

Appendix A contains a characterization of statins in terms of their ATC code. Statins are paneled into eight different ATC classes, of which six are marketed in Denmark. Statins are not the only LMAs; there exist others, such as fibrates or nicotinic acid. However, according to the "Institute of Rational Pharmacotherapy" (Institut for Rational Farmakoterapi, IRF), which is a governmental agency under DKMA, these products are only prescribed under special circumstances, for example, because of intolerance to statins or if the patient has very high levels of triglycerides, a lipid that is very harmful to the coronary system.

Medical practitioners must request health insurance subsidies for statins from DKMA for their patients, which is a formality if critical cholesterol levels exceed a given threshold. Health insurance subsidies for LMAs other than statins must be applied for with a separate request.

Appendix B displays the market shares of LMAs corresponding to each four digit ATC code. This shows that the market share of statins is well above 90 percent during the relevant time period.

\footnotetext{
${ }^{9}$ An earlier version of this paper measured prices and quantities in per-pill units instead of DDD. This led to qualitatively similar but larger effects of the reform.

${ }^{10}$ Our price change estimations include 90 products only because five products did not change their price at all in the base period or the treatment period so that parameter estimates for these products could not be obtained. In the reform effect analysis that follows, we substitute the missing price changes with observed price changes for these products.
} 


\section{Prescription behavior}

We spoke to medical practitioners from internal medicine and neurology as well as to a general practitioner about their prescription behavior. When treating a patient, they follow the recommendations issued by IRF and simultaneously choose the active ingredient and dosage.

\section{Substitutes}

Patients can only substitute among products with the same active substance and strength as indicated by the prescription. ${ }^{11}$

Medical practitioners in Denmark tend to regard all statins as perfect substitutes, at least with respect to their effects on cholesterol levels and slightly less so with respect to their resorption. Indeed, IRF (2003) discusses a "group effect" of statins, which means that the effect of statins is independent of the specific choice of statin, which reinforces doctors' perceptions of statins as highly substitutable. In fact, doctors may substitute, for example, one daily pill of simvastatin $40 \mathrm{mg}$ with either two pills of simvastatin $20 \mathrm{mg}$ or a half pill of simvastatin $80 \mathrm{mg}$.

It is not clear a priori if and to what extent Danish medical doctors and patients are price sensitive. IRF does, however, issue recommendations to substitute one product by another if (i) it has been demonstrated in clinical studies that the effects are identical, and (ii) one of the products is substantially cheaper than the other. For example, in 2008, IRF made an explicit recommendation to substitute the statin atorvastatin $10 \mathrm{mg}$ with another statin, simvastatin $40 \mathrm{mg}$ (IRF 2008).

If doctors and patients decide that medical treatment is needed, doctors decide which product group (ATC group) to take based on the medical record of the patient and possible intolerance to one or more of the ingredients. For example, the doctor may first decide to prescribe simvastatin. Given that choice, she then decides on the strength of the product to be taken given the deviation between the actual and targeted cholesterol level as well as the weight and gender of the patient, for example, $40 \mathrm{mg}$ of simvastatin. Given the product group and strength combination, patients decide which of the products within this combination to buy. In the case of $40 \mathrm{mg}$ simvastatin, they may chose from 12 different products.

\subsection{Source}

Prices, reimbursement status and other product characteristics are published at www.medicinpriser.dk. The website, which is maintained by DKMA, has been available since 1998. It contains, however, only data for five consecutive years at any point in time.

\footnotetext{
${ }^{11}$ The Danish definition of substitute groups includes package size, but package size may not vary by more than ten percent within substitution groups.
} 
The site publishes a list of all authorized pharmaceutical products marketed in Denmark. Prices are updated every second Monday based on changes reported by producers during the last two weeks since February 2003. The database is publicly available and was created to help citizens calculate their reimbursement rates and to inform them about alternative substitution options. The site www.medicinpriser.dk is also used by general practitioners when issuing prescriptions, by hospitals for their electronic patient records and by pharmacies to ensure uniform prices for prescription drugs at a national level.

We merged the fortnightly pharmacy retail prices with information on sales volumes. Our sales volume data are proprietary and were made available to us by LIF. These data have the same periodicity as the price data. Table 3 presents a descriptive overview of prices and the competitiveness of the statins market during the two considered periods. Prices are in 2005 Danish Crowns (DKK). Table 3 contains information on all statins, not just those that were on the market both before and after the reform.

Insert Table 3 about here.

List prices per DDD decreased on average by 35 percent from the base period to the implementation period. Reference prices decreased by 39 percent on average, while co-payment prices decreased by 12 percent on average after implementation. Sales, measured in DDD sold every 14 days, increased by four percent on average.

The average number of products in each period varied between 125 and 126, while the average number of producers in each period increased over time from 19 to 23 . Producers that belong to the same company form a conglomerate. There were 15 to 16 conglomerates at any point in time.

While the share of branded products steadily decreased over all periods, the two measures of concentration (namely, the Herfindahl Index and the three-firm concentration ratio) increased over time, reaching averages of 0.26 and 0.7 , respectively.

\section{Theoretical considerations}

To better interpret the later empirical results, we find it useful to outline the expected effects of the reform. This discussion is partly based on Kaiser et al. (2010), who analyze the effects of the Danish reference price reform using a simple Hotelling model of competition. ${ }^{12}$ Because the reference price is defined at the level of substitution

\footnotetext{
${ }^{12}$ There are several papers that analyze the effects of reference pricing. However, Kaiser et al. (2010) is, to our knowledge, the only paper that compares the specific systems used in Denmark before and after the reform.
} 
groups, we focus primarily on the effects of the reform on intra-substitution group competition.

We organize our discussion along two dimensions, namely, (1) substitution groups with a minimum list price, $p_{\min }^{l}$, below, above or equal to the reference price, $p^{E U}$, before the reference price reform and (2) marginal and infra-marginal patients. In line with our discrete choice model of demand, marginal patients are defined as those for whom the relevant choice is whether or not to buy any statin or, to use the words of the demand model discussed in Subsection 7.1, whether to buy one of the "inside goods" or an "outside good." Instead, the relevant choice for infra-marginal patients is which product to buy. ${ }^{13}$

\subsection{Substitution groups where $p_{\min }^{l}<p^{E U}$}

Let us start by considering substitution groups with two or more products. Before the reference price reform on April 1, 2005, there was an external reference price, $p^{E U}$. This meant that the incentives of infra-marginal patients to choose the cheapest product were muted if $p_{\min }^{l}<p^{E U}$ because the patients only paid a fraction of the price difference when buying a more expensive product (i.e., 20 percent of the price difference up to $p^{E U}-p_{\min }^{l}$ and 100 percent thereafter). An implication of this system is that demand is less price elastic below $p^{E U}$ than above this threshold (Danzon and Liu, 1998). After the reform, the infra-marginal patients paid the full price difference out-of-pocket when buying a more expensive product. We expect this change to make the infra-marginal patients more price sensitive, thereby increasing competition for these patients. Regarding the marginal patients, they look at absolute co-payments rather than price differences when making their purchase decisions. The reform results in higher co-payments at pre-reform list prices due to lower reimbursement from public health insurance. Higher patient co-payments, in turn, translate into a demand reduction from the marginal patients. We expect both intensified competition for infra-marginal patients and the demand reduction of marginal patients to result in lower prices after the reform.

In substitution groups with only one product, all patients are marginal by definition. Some of these patients stop buying the product at pre-reform prices after the reform due to the increased co-payment. Again, this corresponds to a demand reduction resulting from the reform, which we expect to result in a lower price.

\footnotetext{
${ }^{13}$ This way of conceptualizing competition inside a substitution group is similar to the framework used in Miraldo (2009). She models the market as a Hotelling line with open ends, with firms located at zero and one. In her model, the infra-marginal patients are those located between the firms and, the marginal patients are those located at the borders of the market.
} 


\subsection{Substitution groups where $p_{\min }^{l}>p^{E U}$}

In substitution groups with two products or more, the reference price reform does not affect competition for the infra-marginal patients because these patients were already paying the full price difference between any two products before April 1, 2005. Hence, the effects of the reform are driven by the change in the demand of the marginal patients in all substitution groups. Because $p_{\min }^{l}>p^{E U}$, the reference price reform results in a larger reimbursement of and lower co-payments for the pre-reform list prices. We expected this to increase the demand of marginal patients and to result in higher prices after the reform.

\subsection{Substitution groups where $p_{\min }^{l}=p^{E U}$}

In substitution groups where $p_{\min }^{l}=p^{E U}$, the reference price and the co-payments do not change as a result of the reform with respect to pre-reform list prices.

Furthermore, the patients paid the full price difference between any two products already before the reform. Hence, following this logic, the reference price reform changes neither competition for marginal patients nor competition for infra-marginal patients. We expect the reform to have no effect on prices and demand here.

\subsection{Discussion}

The discussion above outlines the effects of the reform on prices across different substitution groups. Still, there are a number of other factors that could moderate these effects.

First, we focused on intra-substitution group competition in the discussion. This corresponds to competition resulting from patients who are issued a prescription by a medical practitioner such that a switch to a different substitution group is no longer possible, at least not without another visit to a medical practitioner. It is likely that the medical practitioner and the patient consider the price levels in the different substitution groups before a prescription is issued, e.g., by choosing among pills of different strengths or packages of different sizes. If so, this introduces inter-substitution group competition. We expect such competition to reduce price levels generally and specifically to reduce the price differences between substitution groups that result from the reform.

Second, it is possible that producers operating in several national markets are reluctant to decrease their prices on the Danish market in order to keep prices up on other markets. A low price on the Danish market may, e.g., undermine a firm's bargaining position when negotiating prices with other health authorities or may reduce reference 
prices calculated on the basis of international prices. We expect this to make producers reluctant to reduce prices but willing to increase prices after the reform, which should thus work against finding a negative average effect of the reform on prices.

Third, increasing and decreasing prices should induce entry and exit, respectively. We expect that this endogenous adjustment in the market structure due to the reform reduces the magnitude but not the sign of the price changes discussed above.

\section{Price effects of the reform}

\subsection{Price effects}

\section{Changes in list prices}

The central prices to consider in the Danish health care market are the list prices because the reference prices (at least after the reform) as well as co-payments are mechanically derived from the list price as described in Subsection 3.3. We therefore link the effect of the change in the reference price system to the list price of each product during the base and treatment periods. We acknowledge that the reform effects may be widely divergent across products, which is why we allow for full flexibility in our estimates by allowing the mean reform effects to be different for different products. In other words, we estimate average changes between the base period and the treatment period, product-by-product. We do so by regressing list prices per DDD on a constant term and a dummy variable for the treatment period. The corresponding parameter estimate constitutes our product-specific estimate for the effects of the reference price reform on list prices. Our estimated price changes combine the "direct" effect of health care reform through changes in the pricing strategy of producers as well as "indirect" effects arising from entry and exit, possibly induced by the reform.

Insert Table 4 about here.

Table 4 displays PMGE and fixed effects estimation results for our regressions of dummy variables for the implementation (that is, treatment) period as well as a constant term. The estimation involves 90 products that existed both during the base and implementation periods that were observed at least two times in each period to have a sufficient product-specific time series of prices. There is little difference in the point estimates of the PMGE and the fixed effects results, but standard errors are smaller for the fixed effects estimation, which is a direct consequence of fixed effects imposing more structure on the data. We shall use the product-specific estimation results in the following analysis. Our discussion refers to the PMGE results in Table 4. The table shows that the reform was associated with a highly statistically significant general decrease in prices per DDD of 1.8 DKK. 
Our interest is, however, not only in the average effect of the reform on list prices per DDD but also in the distribution of these effects within and across substitution groups. The theoretical considerations in Section 5 suggest that prices decrease in substitution groups where $p_{\min }^{l}<p^{E U}$ and increase in substitution groups where $p_{\text {min }}^{l}>p^{E U}$ as a result of the reform. We must deal with two issues when defining initially cheap and initially expensive products empirically. First, we cannot observe $p^{E U}$ directly. For this reason, we have to divide the substitution groups into those for which $p_{\min }^{l} \leq p^{E U}$ (hereafter termed the "cheap" substitution groups) and those for which $p_{\min }^{l}>p^{E U}$ (hereafter termed the "expensive" substitution groups). Note that as we expect no effect from the reform on prices in the substitution groups for which $p_{\text {min }}^{l}=p^{E U}$, we expect a price reduction on average in the cheap substitution groups. Second, prices vary within our base period. Some substitution groups may therefore sometimes be categorized as cheap while at other times as expensive. We choose a very conservative definition of the two groups; a substitution group is termed cheap if the list price of at least one product within that group is smaller or equal to the EU average $\left(p^{l} \leq p^{E U}\right)$ in all periods. Otherwise, it is expensive.

\section{Theoretical predictions and empirical findings}

In line with our theoretical predictions, we find that prices decreased in the cheap substitution groups during the implementation period. However, contrary to our predictions, prices decreased even more strongly in the expensive substitution groups. We explain this divergence between the theoretical predictions and empirical results by noting that the market had not reached its equilibrium market structure in all substitution groups before the reform, which is an implicit assumption in the theoretical discussion. In particular, high prices in the expensive substitution groups would probably have led to entry, e.g., by generic producers and parallel importers, regardless of the reform. If so, the strong decrease in prices can be explained by entry exogenous to the reform. This same argument suggests that there would have been exits from the cheap substitution groups without the reform. Therefore, we are likely to underestimate the price decrease due to the reform in these substitution groups. This explanation for the observed price patterns is supported by the fact that the average difference in the number of products in the cheap and in the expensive substitution groups is 3.5 (i.e., there are 3.5 more products in the cheap group than in the expensive group) in the base period but is only 0.9 in the implementation period. There is convergence in competitive pressure across substitution groups, which probably would have also occurred regardless of the reform.

\section{Asymmetric price effects}

Turning to asymmetric effects of the reform on prices within substitution groups, we 
define cheap and expensive products as products for which $p^{l} \leq p^{E U}$ and $p^{l}>p^{E U}$, respectively. Again, the two groups are conservatively defined. A product is cheap if $p^{l} \leq p^{E U}$ for all periods within the base period. Otherwise, it is defined as expensive. The set of cheap products consists of 41 (of 90) products with a joint market share of 67.5 percent. Relaxing the definition we adopt makes the findings for the two substitution groups more similar.

While patients on average enjoyed a price decrease of 1.8 DKK between the base period and the implementation period, our results from Table 4 indicate that the reform had asymmetric effects across different products. The price of the expensive products fell by $2.8 \mathrm{DKK}$, while the price of the cheap products fell by only 0.6 DKK during the implementation period, indicating that patients who initially purchased more expensive products gained considerably more from the reform than patients who initially bought cheap products. Patients may, however, substitute across different products, which implies that asymmetric price effects alone may not necessarily lead to asymmetric effects on total patient expenditures and surplus. For this reason, we study the full effect of the reform on patients in what follows.

\section{Alternative scenarios}

To further investigate the effects of the reform on reference prices, we consider three different scenarios. In Scenario 1 we assume that both DDD list prices and demand stay constant and that the only change that occurs in the system is the switch from the calculation of reference prices based on European averages to the minimum domestic price (which also changes the co-payment). This scenario does not require any estimation and consists of a purely mechanical change in the calculation of reference prices.

In Scenario 2, we assume that demand remains constant while list prices change according to our product-specific estimates and that reference prices change as a consequence of changes in list prices (and the way reference prices are calculated). Because our estimated average effects of the reference price reform are basically product-specific comparisons of mean prices across periods, Scenario 2 is (like Scenario 1) inherently non-parametric.

Our final scenario, Scenario 3, is the most realistic one. In this scenario, we allow list prices (and hence reference prices and co-payments), the way reference prices are calculated and demand to change.

We shall discuss our findings for Scenario 1 and Scenario 2 in the paragraphs below. Scenario 3 is discussed in Section 7 because it involves demand estimation, which requires further explanation. 


\section{Scenario 1: Constant demand and list prices}

Table 5 displays our results for Scenario 1 and Scenario 2. For Scenario 1, we find an average decrease in reference prices of 4.1 percent. The effects of the reform differ widely across products. The lowest 10 percent reference price changes are below -18.3 percent, while the top 10 percent largest reference price changes are above 5.4 percent.

The changes in co-payments reflect the changes in reference prices. The mean copayment change is 13.0 percent. Patient co-payments increase for more than half of all products in Scenario 1. The total changes in government and patient expenditures are estimated to be -1.3 percent and 3.7 percent, respectively, reflecting a co-payment increase for more than half of all products. A change in the reference pricing system alone that keeps list prices and demand patterns fixed hence leads to small savings in government expenditures and to an increase in patient expenditures.

Insert Table 5 about here.

\section{Scenario 2: Constant demand}

In Scenario 2, we allow both for the mechanical change in the calculation of reference prices and for list prices to adapt to the reform. To calculate the percentage changes in list prices for Scenario 2, we use product-specific estimates from our PMGE estimation. Table 5 shows that median list prices decrease by 24.8 percent, and mean list prices decrease by 26.6 percent. The general decrease in list prices is reflected by a general decrease in reference prices. Their median decrease is 35.2 percent, while the corresponding mean is -31.8 percent. The median change in co-payments is -15.9 percent, while the mean change is -7.5 percent.

For Scenario 2, we estimate a change in total producer revenues of 13.7 percent, a change in total government expenditures of 14.9 percent and a change in total patient expenditures of 10.2 percent. That total producer revenues, government expenditures and patient expenditures increase while median and mean prices decrease appears to be a contradiction. At least 10 percent of the list and reference prices and at least a quarter of the co-payments did, however, increase, and many of the bestselling products, including Pfizer's Lipitor, Ratiopharm's Lovastatin and Sandoz's Simvastatin, raised their prices.

\section{$7 \quad$ Empirical Strategy}

Scenario 3 involves estimating a model of demand for differentiated products. We use the estimates from this demand model along with the estimated changes in prices to predict product demand in the treatment period. That is, we keep the set of available products constant and infer demand for these products after the reform by combining 
price changes and demand function parameters. Our demand model includes all statins that were available in the base period and uses prices, product characteristics and sales data for all 21 fortnightly periods of the base period.

\subsection{Demand Estimation}

\section{Basic setup}

Our demand estimation aims at making predictions for the demand for statins if the health care reform had already been introduced during the base period. We obviously can only compute predicted changes in quantities induced by changes in prices for products that already existed in the base period and that also existed in the treatment period.

We use a nested logit model of demand for differentiated products as our empirical workhorse. Our exposition of the nested logit model follows Berry (1994). We assume that a physician chooses the statin that provides the patient with the highest utility given the IRF recommendation.

Following our arguments in Subsection 4.1, we further assume that the physician first determines the active ingredient (that is, ATC) and strength combination for each patient $i$. This defines $G$ groups of substitute products. Each of the $G$ groups consists of several products. Patients then decide which of the various products in the group of substitutes to buy. They reach their purchasing decision by choosing the product that maximizes their utility. Utility depends upon observed characteristics, $\boldsymbol{x}_{\boldsymbol{j}}$, excluding price, $p_{j}^{c}$, which also determines utility but which is treated separately as well as dummy variables for each of the $G$ substitute groups (that is, ATC/strength combinations), which are interacted with an individual-specific random term, $\zeta_{i g}$. Note that this term is the random coefficient on the group dummies. Omitting time subscripts, patient utility is given by:

$$
u_{i j}=\boldsymbol{x}_{\boldsymbol{j}} \boldsymbol{\beta}+\alpha p_{j}^{c}+\xi_{j}+\sum_{j=0}^{G} d_{j g} \zeta_{i g}+(1-\sigma) \epsilon_{i j}=\delta_{j}+\sum_{j=0}^{G} d_{j g} \zeta_{i g}+(1-\sigma) \epsilon_{i j},
$$

where $\epsilon_{i j}$ is assumed to be an iid Gumbel distributed distributed random variable. The term $\delta_{j}$ is called "mean utility" because none of its components are patientspecific. The only elements of vector $\boldsymbol{x}_{\boldsymbol{j}}$ are product-name dummy variables, which also effectively represent producer-specific fixed effects. Examples of product names are "Crestor," "Lovastatin Alternova," "Lovastatin Ratiopharm," "Simvastatin Ratiopharm," "Simvastatin Sandoz," "Simvastatin Teva," "Zocolip" and "Zocor. All other observed relevant product characteristics like active ingredient, package size and strength are already accounted for by the group dummies $d_{j g}$. However, note that we cannot include product-specific fixed effects because they are poorly identified separate 
from the group dummy variables.

The random variable $\zeta_{i g}$ is common to all products in group $g$. Its distribution function depends on parameter $\sigma$. The nested logit model is consistent with randomutility maximization if $0 \leq \sigma<1$. Individual $i$ 's preferences are perfectly uncorrelated across groups if $\sigma=0$, in which case the model collapses into the simple logit demand model. If $\sigma=1$, preferences are perfectly correlated across groups, which implies that the demand equation can be estimated separately for each group of products.

The distributional assumption on $\epsilon_{i j}$ and the presence of a so-called "outside good" with utility that is normalized to $0\left(\delta_{0}=0\right)$ as defined below lead to the following closed form of product demand.

$$
\ln \left(q_{j} /\left(M-\sum_{k=1}^{N} q_{k}\right)\right)=\delta_{j}+\sigma \ln \left(s_{j \mid g t}\right),
$$

where $\ln \left(s_{j \mid g}\right)$ denotes the natural logarithm of product $j$ 's market share in ATC/strength group $g(g \in G)$ and the term $M$ denotes total market size and implicitly defines the size of the outside good, which is given by $q_{0}=M-\sum_{k=1}^{N} q_{k}$. The outside good is a composite good. It consists of products that are purchased by the patients instead of the "inside products," which in our case are statins. These include, for example, the purchase of homeopathic products, a bicycle or a pair of running shoes. Its price is not set in response to the prices of the inside goods. Note that Scenario 3 collapses into Scenario 2 for $\alpha=0$ and $\sigma=0$, i.e., when demand is completely price-inelastic and preferences are uncorrelated.

\section{Potential market size}

We define total market size as the amount of DDDs that would be sold if all potential patients received medication. We calculate the number of potential patients based on a claim by the Danish Association of Heart Patients (Hjerteforeningen, 2007) that 80 percent of all Danish residents above the age of 50 have a cholesterol level that is too high. That figure may appear large, but given a total population of 5.5 mil., it matches well with IRF's (IRF, 2006) estimate that 2.1 mil. Danish residents above the age of 35 have a total cholesterol level of more than $5 \mathrm{mmol} / \mathrm{l}$. Because DDD is in daily per-patient units, the potential market size can be easily computed as 80 percent of all Danish residents above the age of 50 .

Decreasing potential market size, for example, by assuming a lower fraction of people with cholesterol levels that are too high, generates higher elasticities of substitution. Our assumption of a comparatively large market size of the outside good therefore lets us generate conservative estimates of substitution.

\section{Demand prediction}


Total demand for product $j$ is defined as follows.

$$
\hat{q}_{j}=M \frac{\exp \left(\hat{\delta}_{j}\right)}{\hat{D}_{g}^{\hat{\sigma}} \sum_{g=1}^{G} \hat{D}_{g}^{(1-\hat{\sigma})}} \quad \text { where } \quad \hat{D}_{g}=\sum_{j \in G} \exp \left(\hat{\delta}_{j} /(1-\hat{\sigma}) .\right.
$$

We calculate average demand for each product $j$ based on the average prices in the base period as calculated by our PMGE regression. These averages are predictions for the treatment period and are exact mappings for the base period. In logit-type demand models, there is a perfect match between actual and fitted demand by construction.

\section{Alternative estimators}

Nested logit models of demand have been criticized ever since Berry et al. (1995) introduced the random coefficients model, which is also based on the assumption of iid Gumbel distributed idiosyncratic utility components but which generates much more flexible patterns of substitution. A practical difficulty with the random coefficients model is, however, that its estimation requires prices (or other characteristics) to vary across different markets. This is theoretically discussed by Nevo (2000) and empirically shown by Kaiser and Song (2009). Our price and characteristics data do not vary across sub-markets, as prices and co-payments are uniform across Denmark, which is why we resort to our nested logit model.

As a robustness check, we also estimated a nested logit model with an additional nest for branded versus unbranded drugs, thereby introducing additional flexibility into demand estimation. The additional nest did not, however, prove to be statistically significant on any conventional significance level, which is why we rejected the fourlevel nested logit model in favor of our three-level nested logit model.

Finally, we also included LMAs other than statins in our analysis to investigate if the claim medical practitioners that these products constitute a separate subgroup is corroborated empirically. We indeed find evidence that other LMA products are to be treated separately because their inclusion leads to an estimate of $\sigma$ statistically insignificantly different from one.

\subsection{Identification}

The unobserved characteristics of product $j, \xi_{j t}$, are known to both producers and patients, which implies that prices are endogenous in equilibrium and must be instrumented. Not instrumenting prices leads to downwardly biased estimates of the price coefficient $\alpha$. By the same token, within group market shares, $s_{j \mid g t}$ must be instrumented as well. We estimate our demand equation using GMM, and we justify our instrument choice below.

The obvious alternative to IV estimation is to control for unobserved quality characteristics. In principle, this is possible in our setting because the characteristics of 
pharmaceutical products are also time-invariant. Estimating Equation (2) by fixed effects would hence solve the identification problem. The grouping of products is, however, time-invariant, which makes it impossible to separately identify the fixed effects and the parameters related to the shares within substitution groups.

We make two main identifying assumptions. First, we assume that (unobserved) cost factors are common across products in their own (sub-) market and that other (demand-side) shocks specific to the (sub-) market are not correlated with these factors, an approach adopted by Kaiser and Wright (2006) similar to that used by Hausman and Taylor (1981), Hausman et al. (1994) as well Berry et al. (1995). This implies that prices of other products of the same producer are assumed to be driven by common underlying cost factors associated with a producer's production and distribution. These costs also determine a particular product's price, but they are assumed to be uncorrelated with the unobserved component of mean utility, $\xi_{j}$. This is why the average price of a producer's products in the other sub-markets may serve as instruments for price. We define sub-markets by the type of active ingredient and not by the narrower terms of substitution groups to increase the orthogonality of our instrument.

Second, we assume that (unobserved) cost factors are common across products of other producers in the substitution group. These factors are not correlated with unobserved product characteristics. A product's unobserved quality is therefore assumed not to be correlated with observed product characteristics of the products of other producers in the same segment. We use the average price of the products of other producers in the same segment as an additional price instrument.

We also include a cost-side variable as an instrument for prices (namely, an index for pulp and paper prices) to account for packaging costs. We would ideally interact this cost-side variable with product-specific fixed effects or at least with producerspecific fixed effects to introduce between-product variation in these variables. This, however, led to a statistical rejection of our orthogonality assumption, possibly because we could not include product or producer-specific fixed effects as they are not wellidentified separately from the $G$ substitution group dummy variables we implicitly already take into account.

To instrument within group market shares, we follow Bonnet et al. (2006), who assume that a "suitable" projection of the within group market shares on a hyperplane generated by lagged values generates valid instruments. Identification of the coefficient for within-group market shares is essentially based on the assumption that past market shares are uncorrelated with unobserved product characteristics once product-specific fixed effects are controlled for. To improve the precision with which we estimate the 
within-group correlation parameter, $\sigma$, we also include two lags of that variable. ${ }^{14}$

For an instrument to be valid, it requires two properties. First, there must be no correlation between the instrument and the unobserved product characteristics. Second, the instruments must predict the endogenous variable well. The first property can be verified by tests for over-identifying restrictions. This test yields a test statistic of 7.9, which, given 5 degrees of freedom, generates a marginal significance level of 0.16. We therefore cannot reject that our instruments are orthogonal to the error term in the demand equation. The second property can be informally tested by running "first stage" regressions of the endogenous variable on the explanatory variables and the set of instruments. Clearly, there is no "first stage" in GMM estimation, but if (the joint) statistical significance of the instruments cannot be rejected, evidence that the second property holds is found. Appendix C displays such "first stage" regressions and shows that our instruments are both jointly and separately highly statistically significant. They hence fulfill both statistical requirements for instrument validity.

\section{Demand Effects and Results}

\subsection{Demand effects}

Estimation results for Equation (2) are shown in Table 6. We display both the OLS and the GMM results. They differ quite substantially. The coefficient on co-payment, $\alpha$, is six times larger in the GMM estimation than in the OLS estimation. The coefficient for within-group market shares, $\sigma$, is 4.6 times smaller, which is a typical finding and consistent with our expectations. We shall use the GMM estimates only because these are unbiased and consistent (given the instrument choice).

The coefficient on price per DDD, specified as patient co-payment, is negative and highly statistically significant. It does not have a direct economic interpretation and thus must be converted into price elasticities. The respective formulas are presented in Berry (1994). Our estimated mean own-price elasticity is 0.5 percent, which does not differ much from Gemmill et al. (2007), who summarize estimates for own-price elasticities found in the literature on drug demand.

Insert Table 6 about here.

The within-group correlation parameter $\sigma$ is estimated at 0.13 , which is statistically significantly different from both 0 and 1 . Patient preferences are therefore moderated

\footnotetext{
${ }^{14}$ Our estimated $\sigma$ is statistically significant at the five percent level without including additional lags. Our estimation results do not differ at all with or without these lags, but including them increases the significance of the estimates.
} 
at the substitution group level, which confirms that inter-substitution group competition does exist, but it is weak.

\subsection{Reform effects on prices and demand}

Table 7 displays our estimation results for Scenario 3. The changes in list prices, reference prices and co-payments are exactly the same as in Scenario 2 by construction. We redisplay them merely to facilitate the interpretation of our results. Any additions as compared to Table 5 are the results of changes in demand per DDD as well as our estimates for the per-DDD changes in producer revenues and government and patient expenditures. For Scenarios 1 and 2, these changes coincide with the changes in the respective relevant prices because demand was assumed to stay constant.

Insert Table 7 about here.

We estimate an average increase in sales per DDD of 35.7 percent. However, demand does not uniformly increase for all pills. More than one quarter of the products experienced an increase in co-payments, and per-DDD demand decreased for more than one quarter of the products.

Mean (median) changes in producer revenues are estimated to be -23 (-21.9) percent per DDD, and mean (median) changes in government expenditures are -10.7 (-25) percent per DDD. Finally, mean (median) changes in patient expenditures per DDD are -16.1 (-13.7) percent. These per-DDD changes translate into a positive change in total demand for statins by 1.9 percent, a decrease in producer revenues of 5 percent, a decrease in government expenditures of 5.6 percent, and a decrease in patient expenditures by 3 percent.

The reductions in total revenues, government expenditures and patient expenditures are quite dissimilar to those found in Scenario 2, where we assumed that demand remained constant and for which we found increases in producer revenues, government expenditures and patient expenditures. Once we consider demand changes, the signs of the total effects reverse. This implies both that patients do react to price changes by adjusting total demand and that they switch toward cheaper products. Policy analyses that are based on price changes alone may therefore lead to quite misleading results.

\subsection{Patient surplus}

Patient surplus, or consumer surplus as it is usually called, is the final measure of change induced by the reform that we consider. It is a monetary measure of the attractiveness of the set of products available to patients, including the outside good, 
minus the co-payment that a patient incurs. We use the parameter estimates of our demand model to calculate this measure. It is defined by the maximum value of patient utilities. Under the assumptions of the nested logit model, our estimated net patient surplus, $P S$, is defined as follows (Anderson et al. 1992).

$$
\hat{P S}=\frac{1}{\hat{\alpha}} \ln \left(1-\sum_{g=1}^{G} \hat{D}_{g}{ }^{1-\hat{\sigma}}\right) .
$$

The "treatment on the treated" change in patient surplus between the base period and the implementation period is the surplus change associated with the general price reduction that was induced by the reform. Considering those 95 products that were available in both the treatment and basis periods, we obtain an estimate for patient surplus for the base period of 2.17 DKK per DDD, which translates into a patient surplus of the same amount per day given that patients take one DDD per day. For the treatment period, we find an estimate of 2.35 DKK per DDD, which is an increase in patient surplus by 8.2 percent.

\subsection{Asymmetric price effects}

Table 8 adds evidence on asymmetric reform effects to the preliminary discussion in Subsection 6.1. It contains the same information as Table 7 , but it splits the results between cheap and expensive products. The table shows that relative decreases in list prices as well as in reference prices were not only larger for expensive products than for the cheap ones, but prices of many initially cheap products actually increased due to the reform. Co-payments decrease for initially expensive products, while they increase for the cheap products. Demand decreases for low-price products, but it increases for high-price products.

\section{Insert Table 8 about here.}

These differences are reflected by changes in producer revenues, government expenditures and patient expenditures. They all decreased much less (or even increased) for cheap products than for expensive products. Total producer revenue per DDD decreased by 21.9 percent for expensive products and by 0.7 percent for cheap products. Total government expenditures decreased by 32.8 percent for expensive products and by 1.2 percent for cheap products.

While total patient expenditures increased by 0.9 percent for cheap products, they decreased by 9.75 percent for expensive products.

This asymmetry of the effects between initially expensive and initially cheap products implies that patients who purchased products priced below or at the EU average price before the reform were actually made worse off, while patients who initially 
brought the more expensive products were made substantially better off. Moreover, our results indicate that most of the benefits to government expenditures were due to the initially expensive products.

\section{Robustness checks}

To check if our results critically depend upon our estimated price and within-group correlation parameters, $\alpha$ and $\sigma$, we re-calculated the total effect of the reform on demand, producer revenue and patient expenditures.

If we double $\alpha$, which means we double the own-price and cross-price elasticities of demand, this leads to larger effects from the reform on demand and prices both at the product level and in aggregate. The effects on producer revenues, government expenditures and patient expenditures decrease by around 14 percentage points more compared to the results based on our estimated coefficients. Moreover, while asymmetry of the effects across products remains, the differences become smaller.

If we double $\sigma$, which means we reduce the price elasticities of demand, we find overall effects that differ little from our initial results. Even if we quadruple $\sigma$, the total effect on producer revenues, government expenditures and patient expenditures do not differ by more than 5 percentage points.

\section{Conclusion}

Denmark, which maintains a universal coverage health care system, changed the way reference prices for prescription drugs are calculated on April 1, 2005. Before the reform, reference prices were calculated based on the average European prices within respective substitution groups. Reference prices have been calculated as the national minimum price in the substitution group since then.

This paper investigates the joint effects of the reference price reform on prices and demand for statins, which are products that reduce blood cholesterol levels to prevent cardiovascular diseases. We first estimate the effects of the reference price reform on prices and then estimate a model of demand for differentiated products to finally link the estimated price effects to our demand estimates, which enables us to derive counterfactual results not only for price changes but also for changes in demand, producer revenues, patient expenditures, government expenditures and patient surplus.

Our results support previous studies by finding a substantial decrease in prices as a reaction to the reform. List prices decreased by 26.6 percent on average, and reference prices decreased substantially with an average decrease of 31.8 percent. The 
average decrease in co-payments was estimated to be 7.5 percent. These price changes are associated with an increase in total demand by 1.9 percent per 14 days. Total producer revenues decreased by 5 percent, total government expenditures decreased by 5.6 percent, and total patient expenditures decreased by 3.0 percent. Finally, patient surplus increased by 8.2 percent for those products that existed both during the period before the reform and during the implementation period of the reform.

The reference price reform therefore brought about sizeable reductions in both government and patient expenditures, but the reductions are quite unequally distributed across products, which is a finding that is consistent with Lach and Moraga-González's (2009) study of Dutch gasoline stations. The list prices of initially cheap products (i.e., products that were initially priced at the EU average) decreased by 5.8 percent, and initially expensive products (i.e., products that were initially priced above the EU average) fell by 44.1 percent. Therefore, the patients who purchased cheap products before the reform were made worse off, while patients who initially brought more expensive products were made substantially better off. We also find that prices decreased substantially more for products belonging to expensive substitution groups, relative again to the EU average price, than for products belonging to cheap substitution groups. This result goes against theoretical expectations. We explain this by noting that adjustments in the market structure were driven by differences in competitive pressure across substitution groups rather than by the reference price reform itself.

An important question involves to what extent the experience from the Danish reference price reform can inform policy makers elsewhere. The first issue to notice here is that the change in the calculation of the reference price has surprisingly strong effects. Indeed, the price reductions following the Danish adjustment of the reference price were even larger than the price reductions following the introduction of reference pricing in Germany (Pavcnik, 2002). There is no doubt that reference pricing must be complemented with other rules and regulations for generic competition to work well. Automatic generic substitution, which provides a constant profit margin across products for pharmacies, and a formal application procedure whereby doctors prescribe a specific, more expensive product surely spurred generic competition and helped to realize gains from the reform. Still, we believe that the Danish experience provides some general insights concerning the choice of reference prices. Defining the lowest price in the substitution group as the reference price has a number of properties that stimulate competition. First, because patients pay the full price difference when buying a product that is different from the cheapest one, they are as price sensitive as they would be without reimbursement from the health insurance. More price elastic demand, in turn, results in tougher competition and lower prices. Second, using 
the European average price, or any other external benchmark, as the reference price makes demand more elastic above the reference price than below it. This introduces a tendency for producers to set prices equal to the reference price (Danzon and Liu, 1998; Kaiser et al., 2010). For such a system to work well, policy makers must be able to devise rules that solve the difficult task of setting reference prices close to the competitive level, a problem that they do not face when the reference price is the lowest national price in the substitution group. In this sense, the Danish reference price reform shows that the best institution at setting competitive prices is the market. This view is supported by the Norwegian experience, in which pharmaceutical prices fell significantly when a price cap based on European average prices was replaced by reference prices calculated on the basis of domestic prices, as in Denmark (Brekke et al. 2009a,b).

This paper leaves plenty of space for further research. Our analysis is confined to products that existed both before the reform and after the reform, while it is silent about the reform effects on products that entered or exited in the meantime. Neither can we say anything substantive about the entry-inducing effects of the reform, nor can we make any predictions about the effects of the reform on the entry of new drugs. These issues are clearly of utmost importance, but they are far outside the scope of the present paper. 


\section{References}

Anderson, Simon and De Palma, André(1992), Multiproduct firms: a nested logit approach, Journal of Industrial Economics, 40 (3), 261-276.

Berry, Steven T. (1994), Estimating discrete-choice models of product differentiation, The RAND Journal of Economics, 25 (2), 242-262.

Berry, Steven T.; Levinsohn, James and Pakes, Ariel (1995), Automobile prices in market equilibrium, Econometrica, 63 (4), 841-890.

Bonnet, Céline and Dubois, Pierre (2006), Non linear contracting and endogenous market power between manufacturers and retailers: Identification and estimation on differentiated products, unpublished manuscript, University of Toulouse.

Brekke, Kurt R.; Grasdal, Astrid L. and Holmås, Tor H. (2009a), Regulation and pricing of pharmaceuticals: Reference pricing or price cap regulation, European Economic Review, 53 (2), 170-185.

Brekke, Kurt R.; Holmås, Tor H. and Straume, Odd Rune (2009b), Regulation, generic competition and pharmaceutical prices: Theory and evidence from a natural experiment, Working paper, Norwegian School of Economics and Business Administration, Norway.

Brekke, Kurt R.; Königbauer, Ingrid and Straume, Odd Rune (2007), Reference pricing of pharmaceuticals, Journal of Health Economics, 26 (3), 613-642.

Dalen, Dag M.; Strøm, Steinar and Haabeth, Tonje (2006), Price regulation and generic competition in the pharmaceutical market, European Journal of Health Economics, 7 (3), 208-214.

Danzon, Patricia M. and Liu, Hong (1998), Reference pricing and physician drug budgets: the German experience in controlling pharmaceutical expenditures. Working paper, The Wharton School, University of Pennsylvania.

Gemmill, Marin C.; Costa-Font, Joan and Mcguire, Alistair (2007), In search of a corrected prescription drug elasticity estimate: a meta-regression approach, Health Economics, 16, 627-643.

Hausman, Jerry A. and Taylor, William E. (1981), Panel data and unobservable individual effects, Econometrica, 49 (6), 1377-1398.

Hausman, Jerry A.; Leonard, Gregory and Zona, J. Douglas (1994), Competitive analysis with differenciated products, Annales d'Économie et de Statistique, 34, 159-180.

Hjerteforeningen (2007), Danskerne har for højt kolesteroltal; http://www.hjerteforeningen.dk/sw19716.asp 
Heuer, Alexander; Mejer, Malwina and Neuhaus, Jennifer (2007), The national regulation of pharmaceutical markets and the timing of new drug launches in Europe, WP 437, Kiel Institute for the World Economy, Kiel, Germany.

Institut for Rationel Farmakoterapi (2003), Lipidsænkende lægemidler (C10), http://www.irf.dk/dk/rekommandationsliste/baggrundsnotater/lidpidsaenkende_ laegemidler /baggrundsnotat_for_lipidsaenkende_laegemidler_c10.htm

Institut for Rationel Farmakoterapi (2006), Lipidsænkende behandling, http://www.irf.dk/dk/publikationer/rationel_farmakoterapi/maanedsblad/2006 /lipidsaenkende_behandling.htm

Institut for Rationel Farmakoterapi (2008), Analog substitution - kliniske og $\varnothing$ konomiske resultater, http://www.irf.dk/dk/anmeldelser/studieanmeldelser/analog_substitution.htm

Kaiser, Ulrich; Mendez, Susan J. and Rønde, Thomas (2010), Regulatorische Reform und Pharmapreise: Ergebnisse aus Dänemark, forthcoming in Marktmacht, edited by H. J. Ramser and M. Stadler, Tübing, Mohr Siebeck Verlag.

Kaiser, Ulrich and Song, Minjae (2009), Do media consumers really dislike advertising? An empirical assessment of the role of advertising in print media markets, International Journal of Industrial Organization, 27 (2), 292-301.

Kaiser, Ulrich and Wright, Julian (2006), Price structure in two-sided markets: evidence from the magazine industry, International Journal of Industrial Organization, 24 (1), 1-28.

Kanavos, Panos; Costa-Font, Joan and Seeley, Elizabeth (2008), Competition in offpatent drug markets: Issues, regulation and evidence, Economic Policy, 23 (55), 499-544.

Knittel, Christopher R. and Stango, Victor (2003), Price ceilings as focal points for tacit collusion: Evidence from credit cards, American Economic Review, 93 (5), 1703-1729.

Lach, Saul and Moraga González, Jose Luis (2009), Asymmetric Price Effects of Competition, Tinbergen Institute Discussion Paper 09-049/2.

Merino-Castelló, Anna (2003), The Impact of the Reference Price System on the Pharmaceutical Market: a Theoretical Approach, working paper 524, Universidad Pompeu Fabra, Barcelona, Spain.

Mestre-Ferrándiz, Jorge (2003), Reference prices: the Spanish way, Investigationes Económicas, 27 (1), 125-149.

Miraldo, Marisa (2009), Reference pricing and firms' pricing strategies, Journal of Health Economics, 28 (1), 176-197. 
Nevo, Aviv (2000), A practitioner's guide to estimation of random-coefficients logit models of demand, Journal of Economics $\mathcal{E}$ Management Strategy; 9 (4), 513-548.

ÖBIG, Österreichisches Bundesinstitut für Gesundheitswesen (2008), PPRI Report, http://www.goeg.at/de/GOEG-Aktuelles/PPRI-Report-veroeffentlicht-27Arzneimittelsysteme-im-Vergleich.html

Pavcnik, Nina (2002), Do pharmaceutical prices respond to potential patient out-ofpocket expenses?, The RAND Journal of Economics, 33 (3), 469-487.

Pesaran, M. Hashem and Smith, Ron P. (1995), Estimating long-run relationships from dynamic heterogeneous panels, Journal of Econometrics, 68 (1), 79-113.

Puig-Junoy, Jaume (2007), The impact of generic reference pricing interventions in the statin market, Health Policy, 84, 14-29.

Puig-Junoy, Jaume (2010), A Review of the impact of European Pharmaceutical Price Regulation on Generic Price Competition, forthcoming in Pharmacoeconomics.

Scandinavian Simvastatin Survival Study Group (1994), Randomised trial of cholesterol lowering in 4444 patients with coronary heart disease: the Scandinavian Simvastatin Survival Study, The Lancet 344(8934), 1383-1389.

Tirole, Jean (1988), The Theory of Industrial Organization, Cambridge, Massachusetts: MIT Press. 
Table 2: Summary of events related to changes in the Danish reimbursement system

\begin{tabular}{|c|c|c|}
\hline LIF Agreement & $\begin{array}{l}\text { May } 032001 \\
\text { Apr. } 142003\end{array}$ & $\begin{array}{l}\text { Since } 2001 \text { LIF members and the Danish Ministry of Health } \\
\text { have an agreement on price ceiling running until 2005. Not } \\
\text { all active companies follow the agreement. }\end{array}$ \\
\hline Adjustment & $\begin{array}{l}\text { Apr. } 282003 \\
\text { Sep. } 012003\end{array}$ & $\begin{array}{l}\text { The Danish Medicine Agency starts updating pharmaceuti- } \\
\text { cal prices every } 14 \text { days. Before, reimbursement prices were } \\
\text { set every } 6 \text { months }\end{array}$ \\
\hline $\begin{array}{l}\text { Base - Working } \\
\text { group }\end{array}$ & $\begin{array}{l}\text { Sep. } 152003 \\
\text { Jun. } 072004\end{array}$ & $\begin{array}{l}\text { The Danish Ministry of Health announces to assemble a } \\
\text { working group that is asked to submit proposals regarding } \\
\text { reimbursement rules with the aim to increase competition. } \\
\text { The Association of Danish Pharmacies launches the idea } \\
\text { that reimbursements should be based on the cheapest do- } \\
\text { mestic product within substitute groups. The idea earns } \\
\text { widespread support among leading politicians }\end{array}$ \\
\hline Announcement & $\begin{array}{l}\text { Jun. } 212004 \\
\text { Mar. } 282005\end{array}$ & $\begin{array}{l}\text { The law regarding the new reimbursement system is passed } \\
\text { by the Danish parliament }\end{array}$ \\
\hline Implementation & $\begin{array}{l}\text { Apr. } 012005 \\
\text { Sep. } 252006\end{array}$ & The new law is implemented \\
\hline $\begin{array}{l}\text { New LIF agree- } \\
\text { ment }\end{array}$ & $\begin{array}{l}\text { since } \\
\text { Oct. } 292006\end{array}$ & $\begin{array}{l}\text { The LIF and the government agree upon on a price ceiling } \\
\text { corresponding to the price on } 30 \text { Aug. } 2006\end{array}$ \\
\hline
\end{tabular}




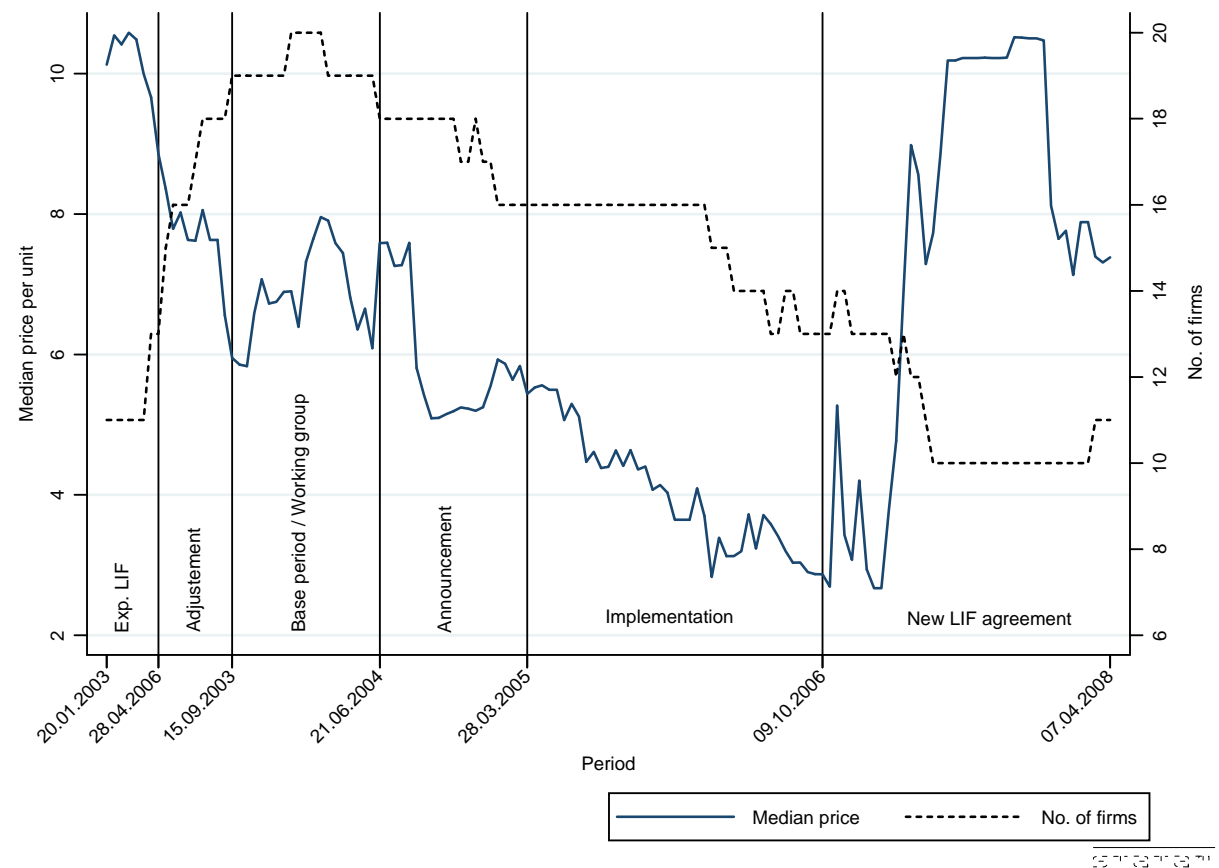

Figure 1: Median price and number of active firms in the market for Statins 


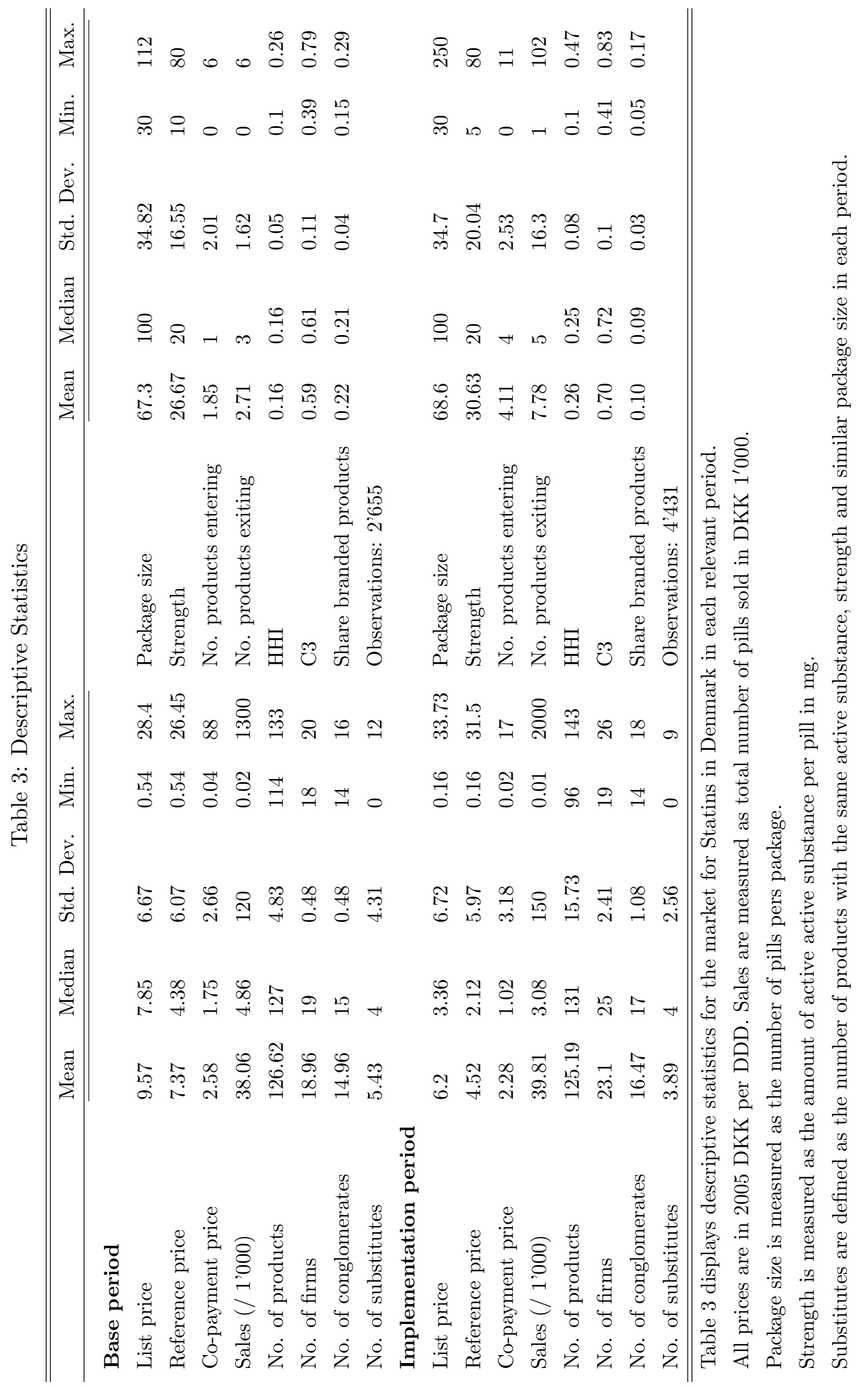




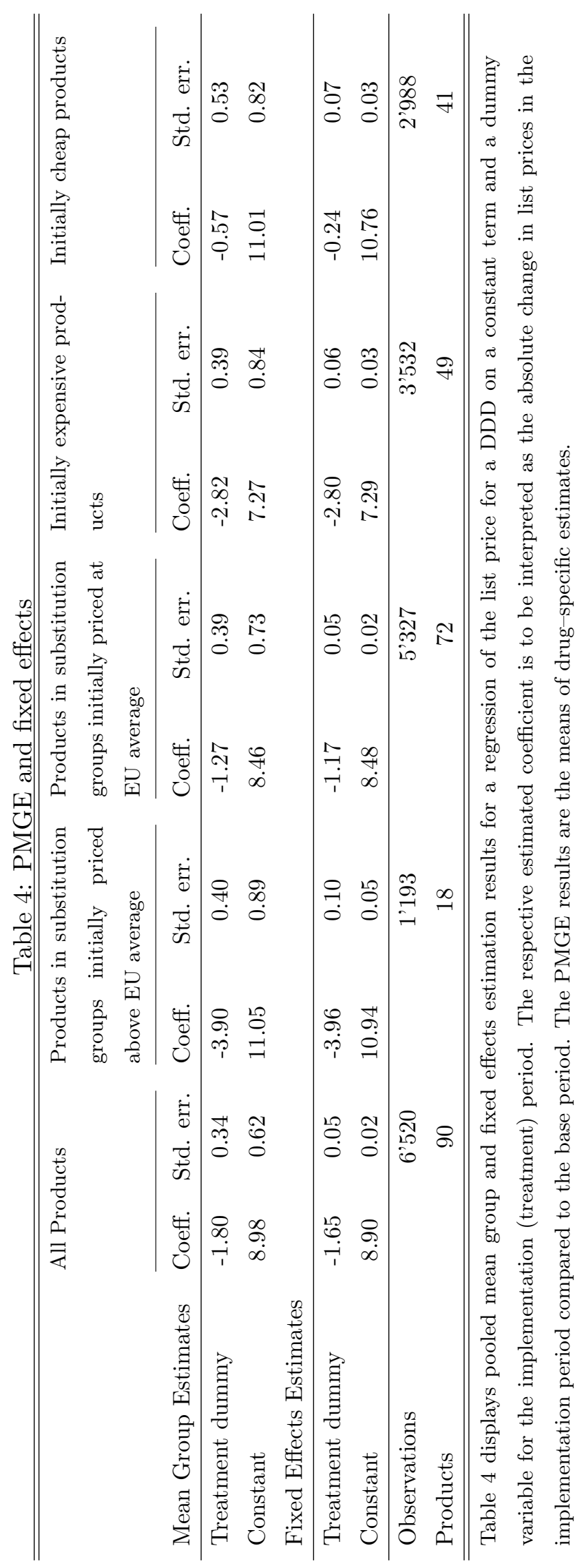




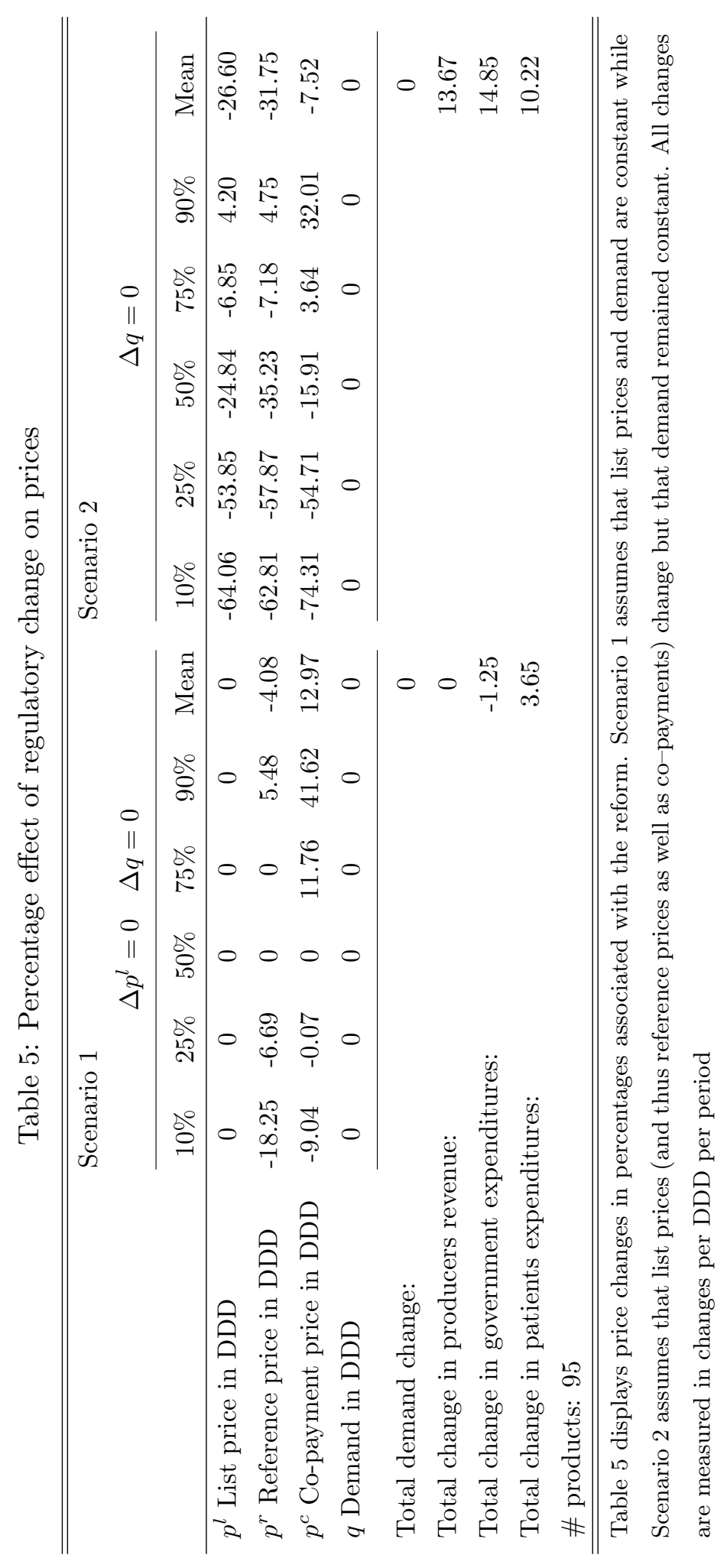


Table 6: Results for OLS and GMM demand estimations

\begin{tabular}{lccccc}
\hline \hline & \multicolumn{2}{c}{ OLS } & & \multicolumn{2}{c}{ GMM } \\
\cline { 2 - 3 } \cline { 5 - 6 } & Coeff. & Std. err. & & Coeff. & Std. err. \\
\hline$\alpha$ & -0.03 & 0.01 & & -0.18 & 0.07 \\
$\sigma$ & 0.60 & 0.02 & & 0.13 & 0.05 \\
Constant & -3.55 & 0.79 & & -6.09 & 8.48 \\
\hline \hline \# obs. & & $2 ' 640$ & & $2 ' 640$ \\
\hline \hline Own price effects (mean) & & & & -0.50 \\
\hline \hline
\end{tabular}

Table 6 displays OLS and GMM estimation results for the demand equation. Standard errors are robust to serial correlation and heteroskedasticity. The specification also includes product name dummies, monthly dummies, quadratic and linear time trends.

Table 7: Percentage effect of regulatory change on prices

\begin{tabular}{lcccccc}
\hline \hline & \multicolumn{7}{l}{ Scenario 3} & & & \\
\cline { 2 - 7 } & $10 \%$ & $25 \%$ & $50 \%$ & $75 \%$ & $90 \%$ & Mean \\
\hline$p^{l}$ List price in DDD & -64.06 & -53.85 & -24.84 & -6.85 & 4.20 & -26.60 \\
$p^{r}$ Reference price in DDD & -62.81 & -57.87 & -35.23 & -7.18 & 4.75 & -31.75 \\
$p^{c}$ Co-payment price in DDD & -74.31 & -54.71 & -15.91 & 3.64 & 32.01 & -7.52 \\
$q$ Demand in DDD & -15.47 & -0.95 & 4.15 & 17.15 & 38.91 & 35.69 \\
\cline { 2 - 7 } Firm revenues & -59.38 & -44.57 & -21.89 & -2.40 & 3.97 & -23.00 \\
Government expenditures & -62.14 & -49.43 & -24.99 & -1.42 & 4.62 & -10.67 \\
Patient expenditures & -66.82 & -47.37 & -13.67 & 2.06 & 16.56 & -16.06 \\
Total demand change: & & & & & & 1.91 \\
Total change in producers revenue: & & & & & -4.96 \\
Total change in government expenditures: & & & & -3.61 \\
Total change in patients expenditures: & & & & & 95 \\
\# products:
\end{tabular}

Table 7 displays price and demand changes associated with the reform. Changes are measured in DDD per period. 
Table 8: Percentage change products in low and high price segment

\begin{tabular}{|c|c|c|c|c|c|c|c|}
\hline \multirow{2}{*}{$\begin{array}{l}\text { Price segment } \\
\text { in base period }\end{array}$} & & \multicolumn{6}{|c|}{ Scenario 3} \\
\hline & & $10 \%$ & $25 \%$ & $50 \%$ & $75 \%$ & $90 \%$ & Mean \\
\hline \multirow{12}{*}{$\begin{array}{l}\text { Products } \\
\text { initially low } \\
\text { priced }\end{array}$} & $p^{l}$ List price in $\mathrm{DDD}$ & -36.59 & -22.08 & -6.85 & 2.82 & 7.65 & -5.76 \\
\hline & $p^{r}$ Reference price in DDD & -58.12 & -28.80 & -7.13 & 2.82 & 7.65 & -15.22 \\
\hline & $p^{c}$ Co-payment price in DDD & -26.73 & -13.27 & -0.83 & 7.65 & 69.71 & 30.72 \\
\hline & $q$ Demand in DDD & -33.15 & -1.71 & 0.42 & 3.07 & 11.04 & -6.09 \\
\hline & Firm revenues & -45.71 & -20.18 & -4.52 & 1.80 & 3.83 & -14.71 \\
\hline & Government expenditures & -55.77 & -28.54 & -5.80 & 0.48 & 3.43 & -18.63 \\
\hline & Patient expenditures & -28.54 & -13.88 & -2.12 & 3.26 & 7.63 & 0.95 \\
\hline & \multicolumn{6}{|l|}{ Total demand change: } & -10.60 \\
\hline & \multicolumn{6}{|c|}{ Total change in producer revenue: } & -0.74 \\
\hline & \multicolumn{6}{|c|}{ Total change in government expenditures: } & -1.16 \\
\hline & \multicolumn{6}{|c|}{ Total change in patient expenditures: } & 0.94 \\
\hline & \multicolumn{6}{|l|}{ \# products: } & 42 \\
\hline \multirow{12}{*}{$\begin{array}{l}\text { Products } \\
\text { initially high } \\
\text { priced }\end{array}$} & $p^{l}$ List price in $\mathrm{DDD}$ & -70.27 & -59.50 & -48.31 & -24.14 & -11.99 & -44.04 \\
\hline & $p^{r}$ Reference price in DDD & -66.14 & -59.61 & -48.80 & -34.51 & -16.86 & -44.86 \\
\hline & $p^{c}$ Co-payment price in DDD & -81.14 & -69.34 & -50.28 & -13.34 & 17.69 & -39.52 \\
\hline & $q$ Demand in DDD & -6.17 & 4.53 & 15.19 & 27.36 & 81.45 & 70.65 \\
\hline & Firm revenues & -60.44 & -51.95 & -40.75 & -21.03 & 21.24 & -29.93 \\
\hline & Government expenditures & -63.32 & -55.26 & -43.89 & -21.00 & 29.54 & -4.00 \\
\hline & Patient expenditures & -71.39 & -57.90 & -37.81 & -5.59 & 19.42 & -30.29 \\
\hline & \multicolumn{6}{|l|}{ Total demand change: } & 18.00 \\
\hline & \multicolumn{6}{|c|}{ Total change in producer revenue: } & -21.87 \\
\hline & \multicolumn{6}{|c|}{ Total change in government expenditures: } & -32.78 \\
\hline & \multicolumn{6}{|c|}{ Total change in patient expenditures: } & -9.75 \\
\hline & \multicolumn{6}{|l|}{ \# products } & 53 \\
\hline
\end{tabular}

Table 8 displays price and demand changes associated with the reform for products that initially priced below or equal to the EU average (cheap products) and those that priced above the EU average (expensive products). All changes are measured in changes per DDD per period. 
Appendix A: Anatomical Therapeutic Chemical Classification for C10

\begin{tabular}{|c|c|c|c|c|}
\hline 2-Level & 3-Level & 4-Level & & 5 - Level \\
\hline \multirow{43}{*}{$\begin{array}{l}\text { C10 } \\
\text { Lipid } \\
\text { Modifying } \\
\text { Agents }\end{array}$} & \multirow{38}{*}{ C10A } & \multirow{8}{*}{$\begin{array}{l}\text { C10AA } \\
\text { HMG CoA } \\
\text { reductase } \\
\text { inhibitors } \\
\text { (Statins) }\end{array}$} & C10AA01 & simvastatin \\
\hline & & & C10AA02 & lovastatin \\
\hline & & & C10AA03 & pravastatin \\
\hline & & & C10AA04 & fluvastatin \\
\hline & & & C10AA05 & atorvastatin \\
\hline & & & C10AA06 & cerivastatin \\
\hline & & & C10AA07 & rosuvastatin \\
\hline & & & C10AA08 & pitavastatin \\
\hline & & \multirow{10}{*}{$\begin{array}{l}\text { C10AB } \\
\text { Fibrates }\end{array}$} & C10AB01 & clofibrate \\
\hline & & & C10AB02 & bezafibrate \\
\hline & & & C10AB03 & aluminium clofibrate \\
\hline & & & C10AB04 & gemfibrozil \\
\hline & & & C10AB05 & fenofibrate \\
\hline & & & C10AB06 & simfibrate \\
\hline & & & C10AB07 & ronifibrate \\
\hline & & & C10AB08 & ciprofibrate \\
\hline & & & C10AB09 & etofibrate \\
\hline & & & C10AB10 & clofibride \\
\hline & & \multirow{4}{*}{$\begin{array}{l}\text { C10AC } \\
\text { Bile acid } \\
\text { sequestrants }\end{array}$} & C10AC01 & colestyramine \\
\hline & & & C10AC02 & colestipol \\
\hline & & & C10AC03 & colextran \\
\hline & & & $\mathrm{C} 10 \mathrm{AC} 04$ & colesevelam \\
\hline & & \multirow{7}{*}{$\begin{array}{l}\text { C10AD } \\
\text { Nicotinic acid } \\
\text { and derivatives }\end{array}$} & C10AD01 & niceritrol \\
\hline & & & C10AD02 & nicotinic acid \\
\hline & & & C10AD03 & nicofuranose \\
\hline & & & C10AD04 & aluminium nicotinate \\
\hline & & & C10AD05 & nicotinyl alcohol (pyridylcarbinol) \\
\hline & & & C10AD06 & acipimox \\
\hline & & & C10AD52 & nicotinic acid, combinations \\
\hline & & \multirow{9}{*}{$\begin{array}{l}\text { C10AX } \\
\text { Other lipid } \\
\text { modifying } \\
\text { agents }\end{array}$} & C10AX01 & dextrothyroxine \\
\hline & & & C10AX02 & probucol \\
\hline & & & C10AX03 & tiadenol \\
\hline & & & C10AX05 & meglutol \\
\hline & & & C10AX06 & omega-3-triglycerides incl. other esters and acids \\
\hline & & & C10AX07 & magnesium pyridoxal 5-phosphate glutamate \\
\hline & & & C10AX08 & policosanol \\
\hline & & & C10AX09 & ezetimibe \\
\hline & & & C10AX10 & alipogene tiparvovec \\
\hline & \multirow{5}{*}{$\mathrm{C} 10 \mathrm{~B}$} & C10BA & C10BA01 & lovastatin and nicotinic acid \\
\hline & & combinations & C10BA02 & simvastatin and ezetimibe \\
\hline & & \multirow{3}{*}{$\begin{array}{l}\text { C10BX } \\
\text { combinations }\end{array}$} & C10BX01 & simvastatin and acetylsalicylic acid \\
\hline & & & C10BX02 & pravastatin and acetylsalicylic acid \\
\hline & & & C10BX03 & atorvastatin and amlodipine \\
\hline
\end{tabular}

Appendix A displays a detailed classification of lipid modifying agents with their respective ATC codes.

Source: WHO Collaborating Centre for Drug Statistics Methodology.

Only boldfaced chemical substances are marketed in Denmark. 
Appendix B: LMAs market shares

\begin{tabular}{lllllll}
\hline \hline & 2003 & 2004 & 2005 & 2006 & 2007 & 2008 \\
\hline Statins & 90.91 & 92.50 & 91.92 & 90.53 & 88.89 & 87.04 \\
Fibrates & 6.06 & 4.00 & 3.54 & 4.74 & 3.17 & 3.09 \\
Bile acid sequestrants & 1.82 & 1.50 & 1.52 & 1.58 & 1.59 & 2.47 \\
Nicotinic acid and derivatives & 1.21 & 1.00 & 1.52 & 1.58 & 0.53 & 0.62 \\
Other lipid modifying agents &. & 1.00 & 1.52 & 1.58 & 2.65 & 3.09 \\
Combinations &. &. &. &. & 3.17 & 3.70 \\
\hline Total No. of products & 165 & 200 & 198 & 190 & 189 & 162 \\
\hline \hline Appendix B displays market shares in percentage corresponding to each \\
lipid modifying agents by type and year.
\end{tabular}




\section{Appendix C: First stage results}

\begin{tabular}{|c|c|c|c|c|c|}
\hline \multirow{2}{*}{\multicolumn{4}{|c|}{ price of other products in same group }} & Coeff. & Std. err. \\
\hline & & & & -0.193 & 0.019 \\
\hline \multicolumn{4}{|c|}{ price own products in other groups } & 0.104 & 0.017 \\
\hline \multicolumn{4}{|c|}{ packaging other products in own group } & 0.047 & 0.003 \\
\hline \multicolumn{4}{|c|}{ pulp and paper } & 0.133 & 0.082 \\
\hline \multicolumn{4}{|c|}{ lagged market shares 1} & -4.696 & 1.260 \\
\hline \multicolumn{4}{|c|}{ lagged market shares 2} & -1.635 & 1.593 \\
\hline \multicolumn{4}{|c|}{ lagged market shares 3} & 4.909 & 1.289 \\
\hline & Coeff. & \multicolumn{2}{|l|}{ Std. err. } & Coeff. & Std. err. \\
\hline Name 1 & -1.809 & 0.270 & Name 18 & -6.587 & 0.315 \\
\hline Name 2 & 0.023 & 0.232 & Name 19 & -5.336 & 0.390 \\
\hline Name 3 & -2.004 & 0.268 & Name 20 & -5.839 & 0.188 \\
\hline Name 4 & -0.618 & 0.308 & Name 21 & -6.594 & 0.208 \\
\hline Name 5 & -3.157 & 0.230 & Name 22 & -0.852 & 0.605 \\
\hline Name 6 & -3.793 & 0.325 & Name 23 & -1.614 & 0.300 \\
\hline Name 7 & -3.698 & 0.292 & Name 24 & -0.339 & 0.213 \\
\hline Name 8 & -3.731 & 0.515 & Name 25 & -6.487 & 0.163 \\
\hline Name 9 & -1.622 & 0.201 & Month 3 & 0.112 & 0.192 \\
\hline Name 10 & -6.329 & 0.176 & Month 4 & 0.259 & 0.323 \\
\hline Name 11 & -1.140 & 0.272 & Month 5 & 0.286 & 0.452 \\
\hline Name 12 & 0.221 & 0.240 & Month 6 & 0.231 & 0.630 \\
\hline Name 13 & -5.195 & 0.197 & Month 7 & 0.644 & 0.743 \\
\hline Name 14 & -6.634 & 0.161 & Month 8 & 0.197 & 0.464 \\
\hline Name 15 & -3.939 & 0.275 & Month 9 & 0.170 & 0.345 \\
\hline Name 16 & -5.872 & 0.200 & Month 10 & 0.338 & 0.293 \\
\hline Name 17 & -5.002 & 0.197 & Period 1 & 0.216 & 0.393 \\
\hline Constant & -14.439 & 10.138 & Period 2 & -0.003 & 0.005 \\
\hline \multicolumn{6}{|c|}{ F-test results } \\
\hline \multicolumn{4}{|c|}{ All instruments } & & 99.49 \\
\hline \multicolumn{4}{|c|}{ Price instruments } & & 71.39 \\
\hline \multicolumn{4}{|c|}{ Within groups market shares } & & 110.90 \\
\hline
\end{tabular}

Appendix $\mathrm{C}$ displays the results for the first stage regressions. 